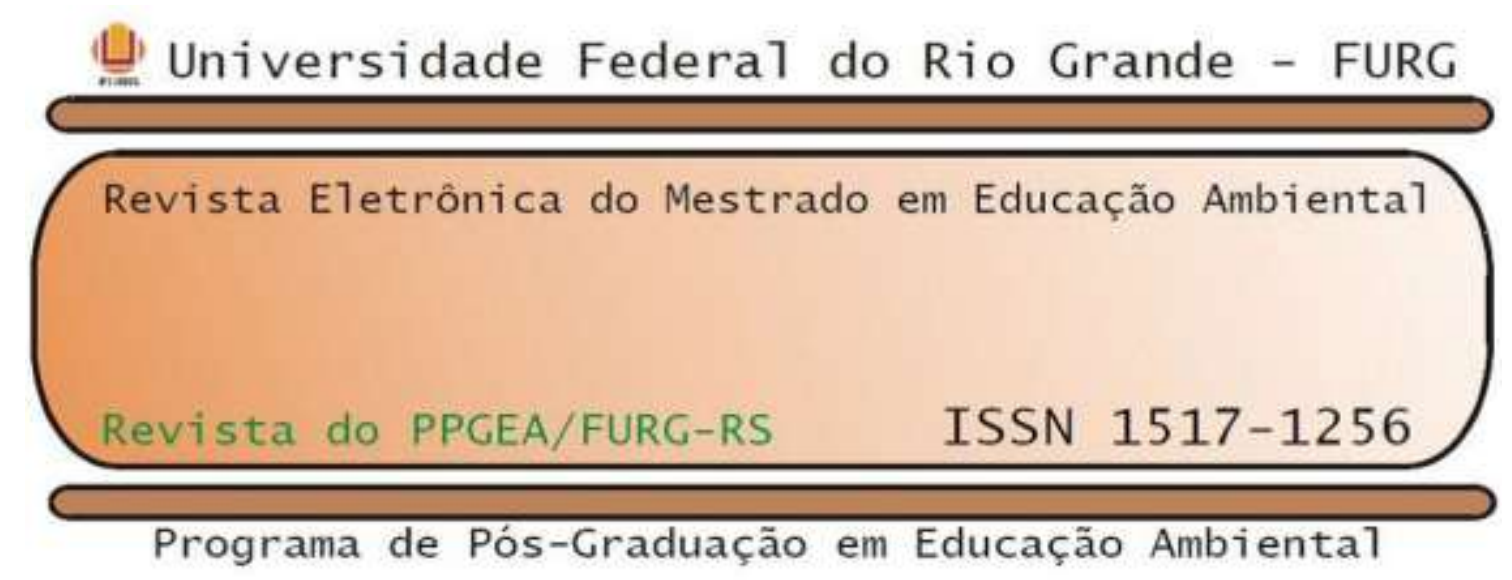

\title{
A Alga, o Índio e a Welwitschia: Storytelling como ferramenta de apoio ao Ensino e à Comunicação de Ciência
}

\author{
Ana Cristina Tavares ${ }^{1}$ \\ University of Coimbra \\ http://orcid.org/0000-0001-8595-218X
}

\begin{abstract}
Resumo: Pela exploração de narrativas sobre o Mundo Natural este trabalho propõe uma comunicação professor-aluno mais provocativa, potenciando maior aproximação à Ciência através de novos instrumentos pedagógicos. Como exemplos que ligam as práticas científicas à realidade quotidiana três livros sobre Biodiversidade e Sustentabilidade para diferentes públicos são apresentados em contexto educativo formal (escolas) e não-formal (Museu da Ciência da Universidade de Coimbra. Com base numa análise caracterizadora das histórias, e de ensaios que se revelaram facilitadores da motivação, compreensão e assimilação de conhecimento, sugerem-se linhas orientadoras e uma dinamização educativa alternativa na prossecução dos curricula escolares. A integrar regularmente no ensino das Ciências Naturais, estes diálogos em storytelling, sendo agregadores de interesses de docentes e estudantes, captam a atenção, estimulam a criatividade e predispõem para novas aprendizagens, práticas reflexivas e interventivas.
\end{abstract}

Palavras-chave: Ciência. Educação. Narrativa.

\section{The Algae, the Indian and Welwitschia: Storytelling as a Supporting Tool for Science Teaching and Communication}

\begin{abstract}
By exploring narratives about the Natural World, this work proposes a more provocative teacher-student communication, enhancing a closer approach to Science through new pedagogical instruments. As examples that link scientific practices with everyday reality, three books on Biodiversity and Sustainability for different audiences are presented in both formal (schools) and non-formal (Coimbra University Science Museum) educational contexts. Based on a characterizing analysis of the stories, and essays that proved to be facilitators of motivation, understanding and assimilation of knowledge, we suggest guidelines and an alternative educational dynamism in the pursuit of school curricula. Integrating regularly into the teaching of the natural sciences, these
\end{abstract}

\footnotetext{
${ }^{1}$ Pós-doutora em Ciências da Educação pela Universidade Católica do Porto, Portugal (2017). Doutorada em Fisiologia Vegetal pela Universidade de Coimbra (2013).e-mail: cristina.tavares@uc.pt.

Rev. Eletrônica Mestr. Educ. Ambient. Rio Grande. v. 36, n. 3. Seção especial: V Congresso Internacional de Educação Ambiental dos Países e Comunidades de Língua Portuguesa. p. 292-318. Set/Dez. 2019.

E-ISSN 1517-1256
} 
dialogues in storytelling, being interest aggregators of teachers and students, capture attention, stimulate creativity and predispose to new learning, reflexive and interventional practices.

Keywords: Science. Education. Narrative.

\section{El alga, la India y Welwitschia : Storytelling como herramienta de apoyo para la enseñanza y la comunicación de las ciencias}

Resumen: Al explorar las narrativas sobre el mundo natural, este trabajo propone una comunicación profesor-alumno más provocativa, mejorando una mayor aproximación à la ciencia a través de nuevos instrumentos pedagógicos. Como ejemplos que vinculan las prácticas científicas con la realidad cotidiana se presentan tres libros sobre Biodiversidad y Sostenibilidad para diferentes audiencias en contextos educativos formales (escuelas) y no formales (Museo de Ciencias de la Universidad de Coimbra). Fundamentado en un análisis característico de las historias y ensayos que demostraron ser facilitadores de la motivación, la comprensión y la asimilación del conocimiento, sugerimos ejemplos y un dinamismo educativo alternativo para la concretización de los planes de estudio escolares. Al integrarse regularmente en la enseñanza de las ciencias naturales, estos diálogos de storytelling, siendo agregadores de intereses de docentes y estudiantes, captan la atención, estimulan la creatividad y predisponen al nuevo aprendizaje y prácticas reflexivas e intervencionais.

Palabras llave: Ciencia. Educación. Narrativa.

\section{INTRODUÇÃO}

Comunicação e educação implicam ligações biunívocas, efetivas se houver uma reação. Para o sucesso de ambas, é fundamental saber envolver a audiência com eficácia (MCKINNON \& VOS, 2015). Mas se é possível comunicar sem ensinar, não é possível ensinar sem comunicar, uma ferramenta primordial no processo educativo. Ensinar exige uma comunicação competente, que acrescente saber e consciencialização para a ação. Educar implica conseguir novo conhecimento, gerador de reflexão e decisões, ou seja, a aquisição de mais-valias cognitivas e comportamentais.

Nos últimos anos, vários estudos têm demonstrado que a narrativa facilita a aprendizagem de Ciência, e que as histórias (ou storytelling) são o ingrediente mais poderoso. Utilizadas para descodificar o conteúdo científico, tornando o conhecimento relevante e acessível aos interesses das pessoas, a narrativa promove o desenvolvimento cognitivo, imaginação, emoções e pensamento. Estes discursos expositivos atraem a atenção, aumentam a curiosidade, ativam a concentração, estimulam a apreensão, envolvem e promovem o interesse, podem ser regenerativos e levar a mudanças comportamentais (AVRAAMIDOU \& OSBORNE, 2009; BIETTI, TILSTON \& BANGERTER, 2018; DAHLSTROM, 2014; JONES, \& CROW, 2017; MARTINEZCONDE E MACKNIK, 2017; MCSILL, 2015; ROSE, 2017).

Rev. Eletrônica Mestr. Educ. Ambient. Rio Grande. v. 36, n. 3. Seção especial: V Congresso Internacional de Educação Ambiental dos Países e Comunidades de Língua Portuguesa. p. 292-318. Set/Dez. 2019. 
As histórias são importantes porque se misturam com a imaginação de quem as ouve, sustentada em interpretações e realidade cultural pessoais e sob múltiplas perspetivas, e o enredo fica intrinsecamente persuasivo e inspirador. Quer se trate de uma formação, reunião, palestra ou no dia-a-dia, uma boa história, bem contada na hora certa, pode ter uma repercussão tão forte que esclarece tudo o que queremos que saibam. Os ouvintes sentem-se parte ativa do acontecimento e conseguem visualizar um mundo universal, cruzando o que lhes é familiar com o que é desconhecido. Através das histórias, a comunicação ganha outro impacto e torna-se cativante para o ouvinte porque tudo parece articular-se na perfeição.

Questões como biodiversidade, evolução, mudanças climáticas e segurança alimentar são hoje críticas e ameaçadores à sustentabilidade mundial e devem fazer parte das preocupações de todos os cidadãos (REIS, LIMA \& DESIDERIO 2018). Estes, por sua vez, devem ser atores e promotores de decisão, através de uma educação que é exigida com maior amplitude e profundidade de conhecimento, em favor da alfabetização e do progresso, constituindo alguns dos principais focos de atuação em centros de ciência, como os jardins botânicos e os museus (DILLON, DEWITT, PEGRAM, IRWIN, CROWLEY, KING, KNUTSON, VEALL \& XANTHOUDAKI, 2016; MATTEMAN \& DAMSA, 2017; TAVARES, 2015). Tem-se revelado muito importante explorar esses temas com alunos jovens (LINDEMANN-MATTHIES, COSTAS, LEHERT, NAGEL, RAPER \& KADJI-BELTRAN, 2011), particularmente com 10 a 14 anos de idade, fase crucial do seu desenvolvimento pessoal (OSBORNE \& DILLON 2008), experiências educativas que podem produzir uma ponderação positiva sobre o desempenho académico, sensibilizando para novas opções numa escala transversal: como aprendiz, e como cidadão politicamente e socialmente ativo (KAPELARI, BONOMI, DILLON, REGAN, BROMLEY, VERGOU \& WILLISON, 2013).

$\mathrm{Na}$ promoção de práticas e pensamentos mais sustentáveis, os discursos cientificos devem ser mais significativos para os cidadãos, criando-se estratégias e diálogos interessantes e estimulantes, que vinculem as experiências à realidade diária e assim possam despertar para as circunstâncias e exigências da atualidade. Neste contexto, revelase importante conhecer as questões e os formatos para a comunicação do texto científico, os componentes e caraterísticas de uma história de Ciência e em que medida podem ser consideradas e utilizadas como técnicas pedagógicas.

Rev. Eletrônica Mestr. Educ. Ambient. Rio Grande. v. 36, n. 3. Seção especial: V Congresso Internacional de Educação Ambiental dos Países e Comunidades de Língua Portuguesa. p. 292-318. Set/Dez. 2019. 


\section{PERGUNTA-PROBLEMA - OBJETIVOS JUSTIFICATIVOS}

A questão de investigação reside em perceber como utilizar as histórias (storytelling) como instrumento de apoio ao ensino e à comunicação da ciência.

Este manuscrito propõe metodologias baseadas em três histórias do mundo natural descreve e analisa procedimentos, ações, reflexões e o impacto de práticas pedagógicas, aplicadas em diferentes contextos de educação em ciência, formal e não formal.

Para isso será importante clarificar o contexto educativo mais comum da aplicação destas 3 histórias, considerado o mais adequado para uma utilização eficaz. Segue-se uma breve apresentação das histórias, sustentadas por factos reais e experiências das Ciências naturais, vocacionadas para públicos e níveis de escolaridade diferenciados:

1. "A alga que queria ser uma flor" (TAVARES, 2013) é um livro ilustrado destinado a crianças da pré-primária até aos 10 anos. A história traduz as principais diferenças morfológicas e a evolução das plantas através do sonho e esforços de uma alga verde que se quer tornar uma flor, e pede ajuda à "Dona Botânica", uma estátua da estufafria do Jardim Botânico da Universidade de Coimbra. Numa primeira etapa, evolui para um musgo, depois um feto, a seguir uma planta com uma pinha e, finalmente, uma planta com flor. Originalmente em português, também está traduzida para inglês, francês, alemão, italiano e espanhol, aumentando o alcance e os contextos de utilização.

2. "O índio que queria conhecer o mundo" (TAVARES \& PEREIRA, 2018) é um livro destinado a crianças dos 6 aos 12 anos; originalmente em português, uma história do mundo natural através das aventuras de dois objetos etnográficos. Mukixi e a sua amiga, Tikuna, percorrem as galerias do Museu da Ciência da Universidade de Coimbra e ao contatarem com exemplares de cinco coleções científicas apercebem-se da importância do conhecimento, da biodiversidade e dos museus (TAVARES, 2018).

3. "Sessenta minutos no deserto com... Welwitschia mirabilis" (TAVARES, 2017a) é uma história para adolescentes e adultos. Originalmente em português, descreve uma viagem feita em 2016 pela autora, em Angola, até ao deserto de Moçâmedes/Namibe, e o contacto vivo, com o ícone botânico e endemismo milenar, confrontando os exemplares seculares e da atualidade, em exposição no Museu da Ciência da Universidade de Coimbra.

Suscetíveis de estimular no interlocutor o desenvolvimento da imaginação e das emoções e a aquisição de uma atitude crítico-reflexiva, facilitadores de conhecimento e da

Rev. Eletrônica Mestr. Educ. Ambient. Rio Grande. v. 36, n. 3. Seção especial: V Congresso Internacional de Educação Ambiental dos Países e Comunidades de Língua Portuguesa. p. 292-318. Set/Dez. 2019.

E-ISSN 1517-1256 
integração num mundo global, pretendem ser exemplos inspiradores para a educação e comunicação em ciência e um incentivo à responsabilidade cívica para a sustentabilidade.

\section{FUNDAMENTAÇÃO - CONTEXTUALIZAÇÃO TEÓRICA}

\section{Comunicação e Educação em Ciência: realidades e perspetivas}

A ciência e a tecnologia estão implicadas em todos os aspetos da vida moderna, nos valores pessoais e na definição das principais decisões, como vacinação, segurança alimentar ou alterações climáticas. No entanto, as descobertas científicas não podem ter um impacto real, sem que as pessoas estejam cientes delas. Para descodificar o conteúdo científico e atrair interesses, a disseminação e a comunicação da ciência devem ser o resultado de uma combinação de expectativas, conhecimentos, competências, crenças e valores, que por sua vez são moldados por influências sociais, políticas e culturais. Em situações do dia-a-dia, se as pessoas puderem assumir rotinas com práticas culturais à luz do conhecimento científico, possivelmente ampliarão a sua ligação com a ciência, gerando novos discursos, especialmente entre as crianças $\mathrm{e}$ as suas familias (AUNOLA, VILJARANTA, LEHTINEN \& NURMI, 2013; FLEER \& HAO 2016; NACIONAL ACADEMIES OF SCIENCES, ENGINEERING, AND MEDICINE, 2016).

A disseminação científica está a desenvolver-se rapidamente, cruzando os campos da comunicação, psicologia, educação, filosofia, política e sociologia, bem como as ciências "tradicionais", como ciências naturais, físicas e computacionais (MCSILL, 2015; BRAY, FRANCE \& GILBERT, 2012). Embora a integração da narrativa num contexto científico seja relativamente recente, tem ocorrido nas últimas três décadas, por exemplo, com a proliferação de temas científicos em peças teatrais (MONTENEGRO, 2016; AMARAL, MONTENEGRO, FREITAS, FORTE. \& GIRÃO DA CRUZ, 2017).

$\mathrm{O}$ ato de criar um conteúdo valioso, relevante e atrativo de forma consistente, faz hoje parte integrante do processo da investigação científica e representa uma parceria potencial entre a disseminação científica e a arte de contar histórias, gerando reações positivas nas pessoas, que criam novas perspetivas, atuando como uma verdadeira ferramenta de marketing (MCSILL, 2015).

$\mathrm{Na}$ verdade, ciência e comunicação são práticas que dependem de fatos, mais persuasivos quando apresentados incluídos numa história. Sobre o "poder" das histórias, a 
investigação académica indica que as histórias convencem mais, com menos argumentos, reduzem a contra-argumentação e ultrapassam os mecanismos naturais de resistência mental à mudança. Para aumentar o poder de persuasão os fatos devem ser estrategicamente embebidos numa história, mesmo sendo fortes e convincentes (KRAUSER \& RUCKER, 2019). Na comunicação de ciência, as histórias representam estratégias para traduzir a complexidade conceitual da informação científica para a linguagem quotidiana, especialmente para públicos não especializados, pois proporciona maior compreensão, interesse e envolvimento (DAHLSTROM, 2014; HILLIER, KELLY \& KLINGER, 2016; AVRAAMIDOU \& OSBORNE, 2009).

\section{Abordagens e cenários no ensino das Ciências}

As narrativas são uma ferramenta divertida e poderosa para informar e consciencializar sobre os conceitos da ciência, para adultos, educadores e crianças, proporcionando um ambiente descontraído e motivador para a educação (BELL, FALK, HUGHES, \& TROXEL, 2016; FLEER \& HAO, 2016). O progresso na educação e pesquisa sobre o desenvolvimento infantil levou à especialização do trabalho educacional em museus, com prática de aprendizagem que incluem a resolução de atividades científicas e problemas da vida real através de perguntas abertas e curiosidades, usando pensamento crítico e criativo, num processo de aprendizagem a partir de e com os objetos (HEIN, 2011; VAN AALDEREN-SMEETS, VAN DER MOLEN, VAN HEST \& POORTMAN, 2017).

No contexto da Botânica, a frequente dificuldade em identificar plantas, reconhecendo a sua importância, potencial e função ecológicos, pode ser explicada pelo crescente declínio de conhecimento e desinteresse geral, conhecido como "plant blindness - cegueira sobre plantas" (RANDLER, OSTI \& HUMMEL, 2012; WANDERSEE E SCHUSSLER, 2001), o que acarreta graves consequências no modo como crianças, jovens e adultos percebem a natureza e agem sobre o meio ambiente. É essencial tornar o ensino da Botânica mais atraente, desenvolver ações que contribuam para o seu reconhecimento social e estimular valores e comportamentos para reverter a tendência atual de declínio da biodiversidade (FANČOVIČOVÁ \& PROKOP, 2011; LAAKSOHARJU \& RAPPE, 2010; LOHR E PEARSON-MIMS, 2005; YOREK, SAHIN E AYDIN, 2009).

Rev. Eletrônica Mestr. Educ. Ambient. Rio Grande. v. 36, n. 3. Seção especial: V Congresso Internacional de Educação Ambiental dos Países e Comunidades de Língua Portuguesa. p. 292-318. Set/Dez. 2019. 
Em Portugal, a Botânica surgiu como parte dos programas nacionais de educação básica, sendo tema de estudos do meio ambiente no primeiro Ciclo da Educação Básica, e na disciplina de ciências naturais no segundo Ciclo da Educação Básica (CALDAS \& PESTANA, 2010; FRACALANZA \& MEGID-NETO, 2003). Para atingir os principais objetivos curriculares da área de ciências, é vital o contato direto de crianças com plantas e espaços naturais, envolvendo-os em atividades que possam representar oportunidades, de excelência, para o desenvolvimento de competências e aprofundamento de conhecimento. Estimulando a leitura nas crianças com temas sobre biodiversidade e conservação, a partir da botânica, a ação educativa pode facilmente tornar-se transversal e combinar abordagens linguísticas e incluir dinâmicas artísticas e performativas, onde a música pode ter um papel promotor e facilitador da compreensão da realidade que nos rodeia (KRAUS, 2017).

Agregar valor ao ambiente formal de sala de aula com cenários de educação não formal, espaços naturais, jardins e museus, espaços informais de divulgação e educação da ciência, proporcionam momentos exploratórios da sensibilidade inata dos alunos, da sua curiosidade, empatia, responsabilidade e de harmonia com esses ambientes. Museus de história natural e ciência, centros de ciência e jardins botânicos são instituições promotoras de uma ampla gama de propósitos e atualmente chamados a desempenhar um papel crítico como catalisadores para a compreensão da sociedade e na preparação dos cidadãos para o futuro. Ao propor ações criativas numa relação entre educação, mudanças e responsabilização, as instituições podem envolver os participantes em questões científicas relacionadas com a Botânica, propondo alternativas adequadas à biologia convencional e aumentando a alfabetização científica e múltiplas competências (SANDERS, 2007; DRISSNER, HAASE \& HILLE, 2010; FANČOVIČOVÁ \& PROKOP, 2011; TAVARES, SILVA \& BETTENCOURT, 2015).

\section{Narrativa e metáforas - histórias de Ciência como técnica pedagógica}

A Ciência permite interpretar e adaptar ao meio envolvente o que se revela fundamental nas nossas decisões diárias e no modo de entender o mundo, mas frequentemente está distante de muitos cidadãos. Uma comunicação eficiente pode ser a diferença entre esse campo ininteligível e um campo apreensível. Para promover as preferências dos alunos pela ciência, é fundamental influenciar positivamente as suas atitudes em relação à ciência e aos cientistas (VASCONCELOS, TORRES, MOUTINHO, 
MARTINS \& COSTA, 2015). A narrativa pode promover a aprendizagem da ciência, com os alunos participativos da conceção, exploração e reflexão das histórias. Se os professores forem encorajados a explorar estas técnicas pedagógicas, descobrirão um novo conjunto de processos para contar histórias e simultaneamente ensinar ciências (AVRAAMIDOU \& OSBORNE, 2009; ROSE, 2017; VAN AALDEREN-SMEETS et al., 2017). Os efeitos da narrativa sobre a aprendizagem apoiam o ponto de vista de que as histórias aumentam a retenção e a compreensão e as competências interpretativas, contribuem para mudanças na vida e visões adquiridas e preenchem a lacuna entre a ciência e as humanidades (AVRAAMIDOU \& OSBORNE, 2009; ROSE, 2017; ZABEL, 2014).

Os cientistas confiam na metáfora e na analogia, utilizadas como ferramentas indispensáveis para dar sentido aos fenómenos científicos e comunicar as suas descobertas tornando a comunicação mais eficaz porque a permitem generalizar. Apesar da sua utilidade, permanece a discussão sobre o uso de metáforas na comunicação científica, porque podem restringir o raciocínio científico e contribuir para mal-entendidos e, por vezes, inadvertidamente, reforçar estereótipos. O papel da metáfora como ferramenta científica legítima ainda é controverso, em parte, pela relação entre a exigência de clareza e rigor versus a necessidade de expressões metafóricas, abertas, na linguagem científica (FREZZA, 2016; TAYLOR \& DEWSBURY, 2018).

A literatura considera quatro principais formatos de texto científico para comunicar ciência: expositivo, argumentativo, narrativo e misto (narrativo e expositivo), sendo o elemento mais influente o storytelling, considerado um subconjunto da narrativa.

\section{Storytelling}

Concedendo ao orador o benefício da dúvida ou aceitando o seu ponto de vista, as histórias têm o poder de nos atrair e mudar as nossas atitudes e opiniões, mesmo quando os fatos em si são fracos ou inconclusivos (KRAUSE \& RUCKER, 2019), sendo amplamente reconhecida a importância de se desenvolver empatia com a audiência (VON MOSSNER, 2017) A comunicação científica não é exceção e os profissionais devem concentrar-se nas necessidades, prioridades e imaginação dos ouvintes para conseguir estabelecer uma forte ligação o público (BRAY et al., 2012), e identificar e articular claramente a questão em análise, sob pena de se perder a narrativa, ou ser mal interpretada (JONES \& CROW, 2017).

Rev. Eletrônica Mestr. Educ. Ambient. Rio Grande. v. 36, n. 3. Seção especial: V Congresso Internacional de Educação Ambiental dos Países e Comunidades de Língua Portuguesa. p. 292-318. Set/Dez. 2019. 
Contar histórias é facilmente apreciado e particularmente importante e habitual com as crianças. Tanto a leitura como a audição das histórias podem estimular a conquista de novas competências e o desenvolvimento da imaginação e das emoções, fundamental para o processo de compreensão dos fenómenos, sendo a narrativa mais desafiadora e facilmente relacionável, resultando numa retenção mais efetiva das informações (KEYSERS \& GAZZOLA, 2009; ZACK, 2015). É compreensível, então, que as narrativas também possam ser usadas como ferramentas estratégicas para a comunicação e a educação em ciência, e potencialmente adaptadas a qualquer público.

Uma história pode definir-se como um relato de eventos ligados, expresso por um narrador através do tempo e da ação, enfatizando uma perspetiva pessoal ou uma relação causa-efeito. A narração de histórias, ou storytelling, depende das circunstâncias, podendo ser formal, não formal ou informal, com sessões planificadas, ensaiadas ou acontecendo de modo espontâneo, alcançando cada ouvinte com a sua própria individualidade e experiência de vida. No contexto de uma aula, é útil contemplar os seguintes elementos (AVRAAMIDOU \& OSBORNE, 2009; JONES \& CROW, 2017; ROSE, 2017):

1. Principio: explica os personagens e o contexto; uma cadeia de eventos, incluindo ideia, fatos e estratégias relacionados com o tema. Alguns são relativamente fixos e estáveis, como parâmetros constitucionais, e outros, como descobertas científicas, podem ser apresentados com significados variáveis para diferentes atores.

2. Meio: considera um cenário onde a tensão se constrói, a ação aumenta e os personagens enfrentam um desafio; um discurso, o meio pelo qual o conteúdo é comunicado; o instrumento emocional das histórias, incluindo vítimas, vilões e heróis, os atores que causam e experimentam eventos numa tensão dramática; as posições dos personagens dentro da configuração no tempo e no espaço, estabelecendo relacionamentos e determinando quais elementos estão ativos, inativos ou omitidos.

3. Fim: apresenta a resolução do conflito, o modo como os personagens evoluíram, com uma moral associada.

4. Moral: um objetivo, a mais-valia que o ouvinte deve levar; uma solução para o problema, mensagens para o envolvimento do público. Se bem contada, a história deve maximizar a capacidade de recordar a moral que muitas vezes é uma solução para o problema ou desafio proposto.

A mesma definição geral de storytelling se aplica nas histórias de Ciência: são um relato de eventos ligados, com ações e experiências de personagens reais ou imaginários 
através do tempo e da ação, em que o narrador amplifica um ponto de vista ou mensagem. Há um princípio, que explica os personagens e o contexto, um meio ou seja, um cenário onde a ação se constrói, a pressão aumenta e os personagens enfrentam um desafio; e um fim, a resolução do conflito, com uma moral associada, uma solução para o problema, com a aquisição de conhecimento, entendendo-se as questões científicas e um apelo claro à ação.

$\mathrm{Na}$ verdade, o paralelismo com a ciência não podia ser maior: na sua forma mais simples, uma história é a ligação entre causa e efeito. As histórias de ciência descrevem ações e experiências de personagens reais ou imaginários. Os cientistas desenvolvem um argumento e apresentam o relato, com a descrição de uma série de dados - "narrativas científicas" - ou "narrativas da natureza", em que plantas, animais ou objetos materiais são os protagonistas da ação. (AVRAAMIDOU \& OSBORNE, 2009).

As explicações científicas são análogas às "histórias", na medida em que concebem um elenco de protagonistas, que encenam uma sequência de eventos que têm consequências ou propósitos, e podem ajudar a comunicar a ciência. Alcançar toda uma audiência enquanto comunica o conteúdo científico é tanto uma arte quanto uma ciência, e o sucesso está na estimulação de conexões emocionais com o público (MARTINEZCONDE \& MACKNIK, 2017).

\section{METODOLOGIA}

O objetivo deste estudo é apresentar uma estratégia didática para o ensino das ciências com base em três narrativas e aplicando os conceitos teóricos em diferentes contextos educativos, formal (escola) não-formal (jardim, museu de ciência) e a diferentes níveis escolaridade. Apresentamos as orientações e respostas às questões investigativas, incluindo a estrutura e os planos de aula, os conteúdos e o formato avaliativo para a recolha dos dados durante a exploração educativa.

\section{Caraterização das histórias e objetivos educativos}

Estes livros de TAVARES, "A alga que queria ser flor" (2013), "O Índio que queria conhecer mundo" (2018) e "Sessenta minutos no deserto com... Welwitschia mirabilis (2017) (Fig. 1) constituem elementos originais de comunicação de ciência em 
língua portuguesa, publicados e difundidos para diversos públicos, que passamos a caraterizar:

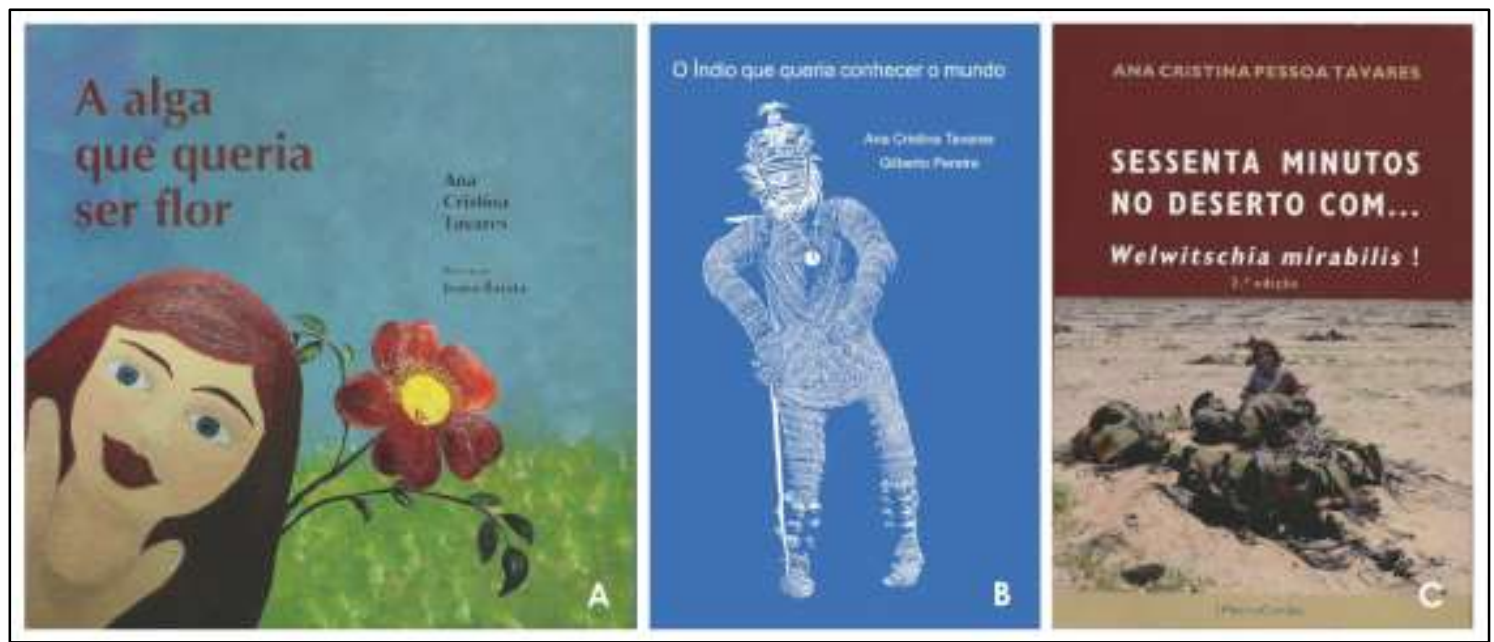

Figura 1: Capa dos três livros: "A alga que queria ser flor" (A), "O índio que queria conhecer o mundo" (B), e "Sessenta minutos no deserto com ... Welwitschia mirabilis" (C).

Estruturalmente, as duas primeiras são narrativas típicas em storytelling, e a terceira é um texto expositivo imbuído em considerações científicas sobre o passado e o futuro do endemismo botânico, também possível de identificar na primeira narrativa, para crianças mais jovens, como uma planta com pinhas e na segunda como um dos exemplares de destaque, por ser raro e ameaçado de extinção e que o museu preserva.

Nas três histórias, os fatos são relatados por ordem cronológica, e organizados num formato típico de três partes essenciais: o começo, o meio e o fim, com uma moral: a mensagem-chave, um novo conhecimento a ser assumido pelo interlocutor. $\mathrm{Na}$ narrativa "A alga que queria ser flor", (pré-primária até 10-12 anos) aplicável em sala ou num jardim, a moral foca-se na distinção e evolução dos cinco principais grupos vegetais, seres vivos a conhecer e respeitar. O livro "O índio que queria conhecer o mundo", (a partir dos 10-12 anos), mostra o mundo natural através da aventura do Mukixi (um objeto etnográfico) pelas galerias do Museu da Ciência da Universidade de Coimbra e a moral pretende o entendimento sobre a importância da Biodiversidade, a sua conservação, que é missão dos museus. Para público mais adulto, a narrativa - expositiva "Sessenta minutos no deserto com... Welwitschia mirabilis!" relata na primeira pessoa, uma viagem por Angola até ao encontro da Welwitschia, um endemismo milenar (Figuras 1 e 2), com uma mensagem clara para a importância da preservação da biodiversidade.

Rev. Eletrônica Mestr. Educ. Ambient. Rio Grande. v. 36, n. 3. Seção especial: V Congresso Internacional de Educação Ambiental dos Países e Comunidades de Língua Portuguesa. p. 292-318. Set/Dez. 2019.

E-ISSN 1517-1256 


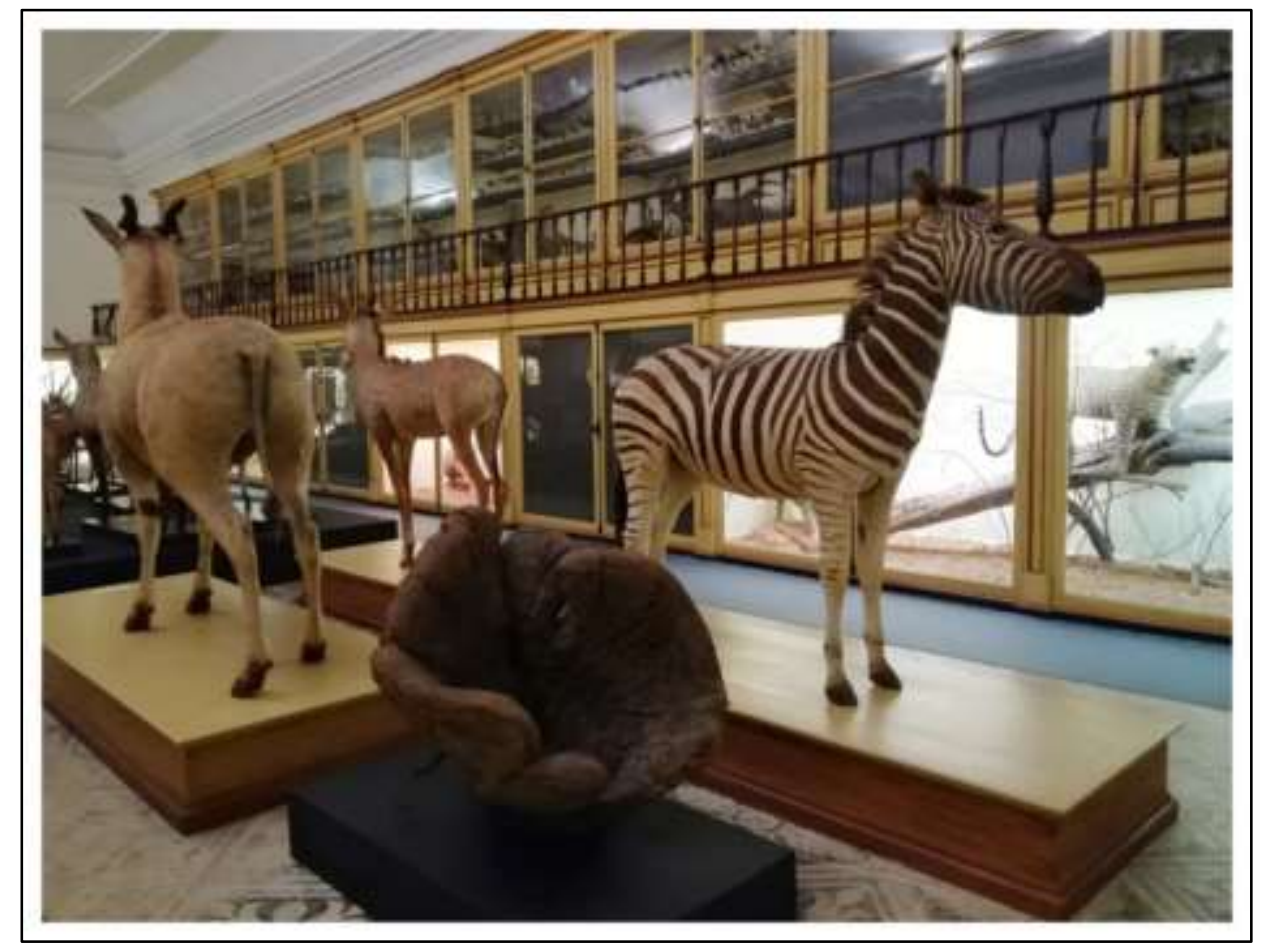

Figura 2: Exemplares de Welwitschia mirabilis Hook do Museu da Ciência da Universidade de Coimbra (BOT.00356). @ Ana Cristina Tavares

\section{Apresentação esquemática da estratégia didática, recolha e análise de dados}

\section{$1^{\circ}$ CASO-ESTUDO: A ALGA QUE QUERIA SER FLOR}

Em parceria com uma Escola e um Professor de Ciências do $5^{\circ}$ ano de escolaridade (primeiro ano do segundo ciclo do ensino básico), os planos de aula de um programa educativo do Jardim Botânico (TAVARES, 2015) foram integrados nas aulas de primeiro e segundo períodos, adotados e ajustados às condições e recursos escolares cumprindo os objetivos curriculares sobre biodiversidade e sustentabilidade. Conduzindo as aulas numa escola e num contexto formal e implementando ambientes não-formais e informais, o foco foi perceber o conhecimento adquirido, as perceções, atitudes e sentimentos dos alunos (10 a 12 anos) sobre a nova experiência escolar, conforme resultados expressos no trabalho de Tavares, Cabral e Alves (2017b).

Em contato direto com exemplares botânicos, a história é comentada com ilustrações, finalizada com uma canção e documentada com algumas fotos do Jardim Botânico da Universidade de Coimbra, e modelos vivos, para explorar e identificar, com base nas características relatadas, conforme ficha de trabalho (Tabela I) e ilustrado na figura 3 .

Rev. Eletrônica Mestr. Educ. Ambient. Rio Grande. v. 36, n. 3. Seção especial: V Congresso Internacional de Educação Ambiental dos Países e Comunidades de Língua Portuguesa. p. 292-318. Set/Dez. 2019.

E-ISSN $1517-1256$ 
Tabela I - Guia da aula "A ALGA QUE QUERIA SER FLOR"

\begin{tabular}{|c|c|}
\hline \multicolumn{2}{|r|}{$\begin{array}{l}\text { Guia para desenvolver os materiais da aula } \\
\text { Tema: A ALGA QUE QUERIA SER FLOR }\end{array}$} \\
\hline $\begin{array}{l}\text { Tópico } \\
\text { curricular }\end{array}$ & $\begin{array}{l}\text { Diversidade nas plantas; plantas sem sementes-musgos e fetos- } \\
\text { Evolução e caraterísticas distintivas dos principais grupos vegetais. }\end{array}$ \\
\hline $\begin{array}{l}\text { Curriculo / } \\
\text { Grau de } \\
\text { ensino }\end{array}$ & $\begin{array}{l}\text { Programa atual do ensino sobre ciências naturais, biodiversidade e } \\
\text { sustentabilidade / pré-escolar até ao } 9^{\circ} \text { ano (idades } 4-14 \text { ) }\end{array}$ \\
\hline $\begin{array}{l}\text { Lista de } \\
\text { materiais }\end{array}$ & $\begin{array}{l}\text { a) projetor de vídeo e data show - projeção e leitura do livro. } \\
\text { b) acesso à internet; } \\
\text { c) lápis de cor e folhas em branco; } \\
\text { d) plantas de diferentes tipos existentes no espaço escolar ou no } \\
\text { exterior (podendo ser os vasos com as plantas: musgos, fetos, ramos } \\
\text { com pinhas e ramos com flores); } \\
\text { e) um frasco com amostras de água recolhida , quanto mais cedo } \\
\text { melhor - uma semana, o ideal, em alguma poça na escola e/ou recolhida } \\
\text { de pequenas pedras, ou mosaicos de exterior, com "manchas verdes", } \\
\text { de "algas" verdes; os procedimentos para recolha das amostras de } \\
\text { microalgas, tanto a partir da água como de pedras, antes da sua } \\
\text { observação microscópica, deverão ser fornecidos } \\
\text { f) Microscópios com lâminas e lamelas, etc. }\end{array}$ \\
\hline & 45-90 Minutos. Duas sessões $-1^{\mathrm{a}}$.em sala; $2^{\mathrm{a}}$.exterior, jardim. \\
\hline Resumo & $\begin{array}{l}\text { - Sala - os alunos ouvem e interagem com plantas, as protagonistas, } \\
\text { seres vivos, da história "A alga que queria ser flor", contada pelo } \\
\text { professor dentro da sala ou num jardim, como o da escola; cantando } \\
\text { com uma mão a evolução das plantas são convidados a ilustrar o que } \\
\text { aprenderam: um desenho, uma nova historia, no formato que } \\
\text { entenderem; finalmente, com a projeção de filmes no jardim, duas } \\
\text { canções sobre "O sonho da alga", os alunos constroem um friso } \\
\text { cronológico com amostras e desenhos dos cinco grupos principais de } \\
\text { plantas } \\
\text { - Num percurso pelo jardim botânico, da cidade ou da escola, os alunos } \\
\text { contactam e observam diferentes plantas e habitats; identificam as } \\
\text { características morfológicas dos principais grupos de plantas são } \\
\text { desafiados a integrar as plantas em cada grupo, colecionando e } \\
\text { classificando plantas diferentes e interpretando os jardins. No } \\
\text { laboratório, com amostras de água de lagoachos com uma semana, a } \\
\text { professora prepara montagens extemporâneas retirando uma gota de } \\
\text { água, e ao microscópio os alunos observam a existência de diferentes } \\
\text { organismos numa gota de água, incluindo as algas verdes. O objetivo } \\
\text { principal é observar e distinguir as plantas, em contexto real, } \\
\text { entendendo a evolução e a diversidade, concretizada nos principais } \\
\text { cinco grupos do reino vegetal, a entender e respeitar como seres vivos. }\end{array}$ \\
\hline $\begin{array}{l}\text { Competênci } \\
\text { as }\end{array}$ & $\begin{array}{l}\text { Esta atividade representa uma abordagem simples aos principais grupos } \\
\text { de plantas e à sua evolução e assim explorar e comparar os principais } \\
\text { grupos vegetais: } 1 \text {. Despertar a curiosidade para a diversidade vegetal e }\end{array}$ \\
\hline
\end{tabular}

Rev. Eletrônica Mestr. Educ. Ambient. Rio Grande. v. 36, n. 3. Seção especial: V Congresso Internacional de Educação Ambiental dos Países e Comunidades de Língua Portuguesa. p. 292-318. Set/Dez. 2019. 


\begin{tabular}{|l|l|}
\hline & $\begin{array}{l}\text { a evolução; 2. Usar e enriquecer a capacidade de observação; 3. } \\
\text { Explorar e desenvolver as competências e ferramentas para alcançar o } \\
\text { objetivo proposto; 4. Construir e aplicar conhecimentos sobre os cinco } \\
\text { grupos e a sua evolução; 5. Reconhecer, respeitar e preservar as plantas } \\
\text { como seres vivos; 6. Conhecer, Interpretar e monitorizar espaços } \\
\text { verdes, como os jardins da Escola. }\end{array}$ \\
\hline $\begin{array}{l}\text { Tipo de } \\
\text { Atividade }\end{array}$ & $\begin{array}{l}\text { Trabalho de exploração em sala e jardim, seguido da aplicação de } \\
\text { novos conhecimentos expressos em desenhos, textos e novas histórias } \\
\text { produzidas pelos alunos. }\end{array}$ \\
\hline $\begin{array}{l}\text { Conhecime } \\
\text { nto prévio }\end{array}$ & $\begin{array}{l}\text { Não é indispensável que os alunos tenham previamente contactado com } \\
\text { os espaços e coleções do jardim, aconselhado para os professores e } \\
\text { educadores }\end{array}$ \\
\hline $\begin{array}{l}\text { Bibliografia } \\
\text { base }\end{array}$ & $\begin{array}{l}\text { Livro multilingue sobre diversidade e evolução das plantas. } \\
\text { http://www.uc.pt/imprensa_uc/catalogo/descobrirasciencias/alga_flor; } \\
\text { Planos de aula adaptado do livro sobre Educação em Ciências: Tavares, } \\
\text { A.C. (2015); - Manual do aluno e do professor. }\end{array}$ \\
\hline Produtos: & Guia de Regras de colheita. Textos pelos alunos. Quadras. Canção. \\
\hline
\end{tabular}

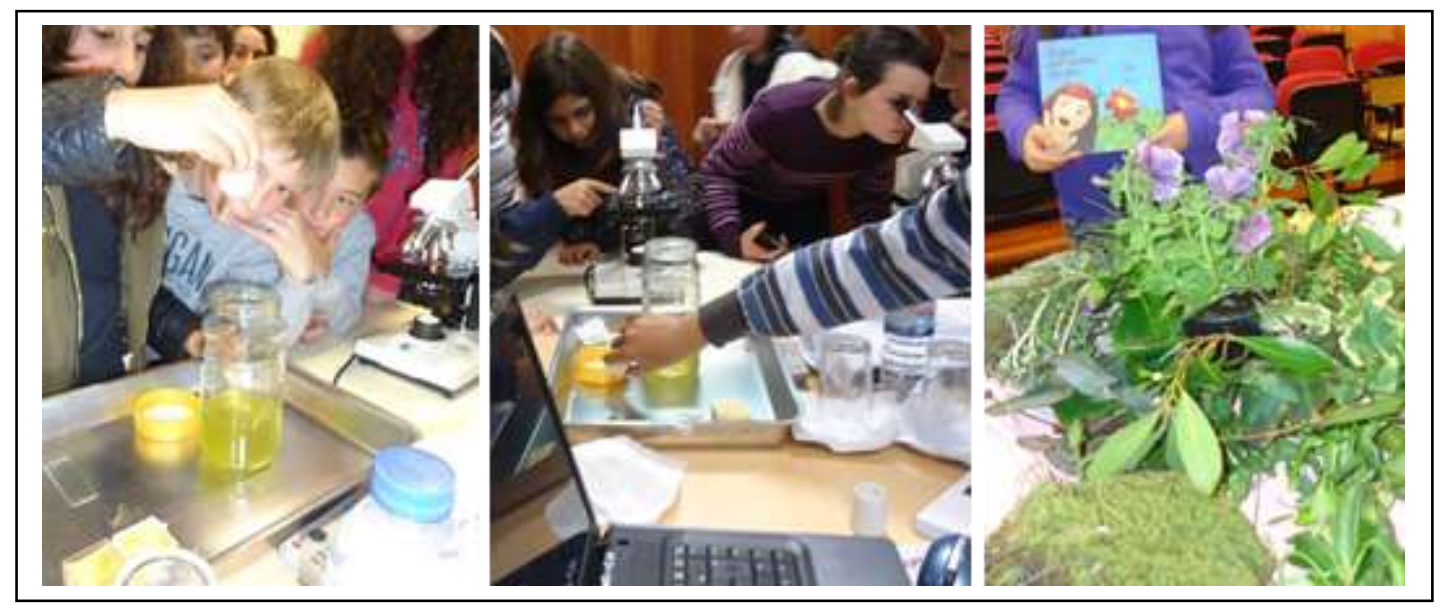

Figura 3 - Diferentes tarefas, individuais e em grupo, durante a aula "A alga que queria ser uma flor. Preparação e estudo pelos alunos de amostras de algas microscópicas do charco da Escola, o livro, a aluna, e as plantas: musgos, fetos, com pinhas e com flor.

Esta história foi também adaptada a uma sessão de formação de formadores num espaço natural, permitindo aos participantes desenvolver trabalho autónomo e de grupo, aplicar conhecimentos novos e prévios, e fazer a interpretação de espaços, in vivo e in situ (TAVARES et al., 2015a). Como reportado por outros autores (PANY, 2014; DILLON et al., 2006; LINDEMANN-MATTHIES, 2005), foi possível despertar nos professores e educadores a curiosidade, e facilitar o conhecimento em Botânica, ao mesmo tempo em que melhoraram a dinâmica das aulas e a aplicação do conhecimento (BROMELY, REGAN, KAPELARI, DILLON, VERGOU, WILLISON, BONOMI, PAIVA, SANTOS. \& TAVARES, 2013).

Rev. Eletrônica Mestr. Educ. Ambient. Rio Grande. v. 36, n. 3. Seção especial: V Congresso Internacional de Educação Ambiental dos Países e Comunidades de Língua Portuguesa. p. 292-318. Set/Dez. 2019. 


\section{AVALIAÇÃo}

O progresso de aprendizagem cognitiva dos alunos na disciplina de Ciências Naturais foi monitorizado e validado por (pré e pós) questionários regulares e posteriormente analisado em entrevista semiestruturada ao professor, que considerou este projeto uma experiência muito positiva (TAVARES, 2017b).

\begin{tabular}{|l|}
\hline \multicolumn{1}{|c|}{ PRÉ-Questionário (em sala, antes da ação) } \\
\hline 1. Na tua opinião, o que são algas, musgos, fetos, pinhas e flores? \\
\hline 2. Se tivesses que os incluir num conjunto mais amplo, qual o nome desse conjunto? \\
\hline 3. Como os poderás identificar e distinguir uns dos outros? \\
\hline 4. Sabes se os poderemos relacionar uns com os outros e porquê? \\
\hline 5. Algum comentário que queiras fazer? \\
\hline
\end{tabular}

\begin{tabular}{|l|}
\hline PÓS-Questionário (em sala, terminada a ação) \\
\hline 1. Aprendi que $\ldots \ldots \ldots \ldots \ldots \ldots \ldots \ldots$ são os $\ldots \ldots$ principais grupos de $\ldots \ldots \ldots$ \\
\hline 2. Aprendi que são $\ldots \ldots \ldots \ldots$ como nós. \\
\hline 3. Aprendi que as características mais importantes que distinguem os grupos são...... \\
\hline 4. Como aconteceu a evolução das plantas? \\
\hline 5. Algum comentário que queiras faze? \\
\hline
\end{tabular}

\section{$2^{\circ}$ CASO-ESTUDO: O ÍNDIO QUE QUERIA CONHECER O MUNDO}

Em parceria com Escolas, Clubes de Ciência e Professores de Ciências do ensino básico, os objetivos curriculares sobre biodiversidade e sustentabilidade foram desenvolvidos em sala e nas galerias do Museu da Ciência, onde dois objectos etnográficos são os heróis de uma aventura. Interagindo com outros exemplares científicos, alguns representando espécies em extinção, e misturando-se imaginação e realidade, despertam-se interesses, a atividade mental e os gostos pessoais, e os participantes aplicam, discutem e refletem sobre os conhecimentos adquiridos. O educador/professor apela à descoberta das personagens da história que são exemplares a encontrar nas galerias do Museu da Ciência interagindo com os objetos; este ensaio explora espaços e recursos de museus, incluindo diferentes coleções científicas (antropologia, botânica, mineralogia, zoologia e física). Conduzindo a sessão num contexto não-formal o foco foi perceber o conhecimento adquirido, as perceções, atitudes e sentimentos dos alunos sobre a nova experiência educativa, conforme ficha de trabalho na tabela II, ilustrado na figura 4 .

Rev. Eletrônica Mestr. Educ. Ambient. Rio Grande. v. 36, n. 3. Seção especial: V Congresso Internacional de Educação Ambiental dos Países e Comunidades de Língua Portuguesa. p. 292-318. Set/Dez. 2019. 


\begin{tabular}{|c|c|}
\hline \multicolumn{2}{|c|}{$\begin{array}{c}\text { Guia para desenvolver os materiais da aula } \\
\text { Tema: O ÍNDIO QUE QUERIA SER CONHECER O MUNDO }\end{array}$} \\
\hline $\begin{array}{l}\text { Tópico } \\
\text { curricular }\end{array}$ & Biodiversidade e sustentabilidade no museu \\
\hline $\begin{array}{l}\text { Curriculo I } \\
\text { Grau de ensino }\end{array}$ & $\begin{array}{l}\text { Programa atual do ensino sobre ciências naturais, biodiversidade e } \\
\text { sustentabilidade / pré-escolar até ao } 9^{\circ} \text { ano (idades 6-14) }\end{array}$ \\
\hline $\begin{array}{l}\text { Lista } d e \\
\text { materiais }\end{array}$ & $\begin{array}{l}\text { a) projetor de vídeo e data show - projeção e leitura do livro. } \\
\text { b) acesso à internet; } \\
\text { c) lápis de cor e folhas em branco; } \\
\text { d) abordagem interpretativa e interativa com os } \\
\text { exemplares/protagonistas do livro presentes nas salas da galeria de } \\
\text { Historia natural do museu }\end{array}$ \\
\hline Tempo previsto & 45-90 Minutos. Duas sessões $-1^{\mathrm{a}}$.em sala; $2^{\mathrm{a}}$.exterior, museu. \\
\hline Resumo & $\begin{array}{l}\text { - Sala - os alunos ouvem a história e são convidados a prestar } \\
\text { atenção aos protagonistas; } \\
\text { - Num percurso pelas salas da galeria do Museu da Ciência em } \\
\text { ambiente de desafio/concurso os participantes interagem com os } \\
\text { exemplares de diferentes coleções do museu, que estão presentes e } \\
\text { a encontrar nos espaços do museu. A interpretação caso-a caso é } \\
\text { feita deixando liberdade e autonomia aos alunos para interpelarem } \\
\text { e explorarem não só os objetos da história do "indio que queria } \\
\text { conhecer o mundo", e outros da sua preferência. O objetivo } \\
\text { principal é observar e distinguir os protagonistas, agira em contato } \\
\text { visual, entendendo a importância das Ciência, da biodiversidade e } \\
\text { da conservação, uma missão dos museus. }\end{array}$ \\
\hline Competências & $\begin{array}{l}\text { Esta atividade representa uma abordagem simples aos princípios e } \\
\text { valores da biodiversidade, conservação e espaços museológicos } \\
\text { focando: 1. Despertar a curiosidade para a biodiversidade e } \\
\text { conservação; 2. Usar e enriquecer a capacidade de observação; } 3 . \\
\text { Explorar e desenvolver as competências e ferramentas para } \\
\text { alcançar o objetivo proposto; 4. Construir e aplicar conhecimentos } \\
\text { sobre Ciência nos museus; 5. Reconhecer, respeitar e preservar } \\
\text { todos os seres vivos e coleções museológicas; 6. Conhecer, } \\
\text { interpretar e utilizar espaços de ensino não-formal, como os } \\
\text { museus. }\end{array}$ \\
\hline $\begin{array}{l}\text { Tipo } \\
\text { Atividade }\end{array}$ & $\begin{array}{l}\text { Trabalho de exploração em sala e no museu, seguido da aplicação } \\
\text { de novos conhecimentos expressos em desenhos, textos e novas } \\
\text { histórias produzidas pelos alunos. }\end{array}$ \\
\hline $\begin{array}{l}\text { Conhecimento } \\
\text { prévio }\end{array}$ & $\begin{array}{l}\text { Não é indispensável que os alunos tenham previamente contactado } \\
\text { com os espaços e coleções do museu, aconselhado para os } \\
\text { professores e educadores }\end{array}$ \\
\hline $\begin{array}{l}\text { Bibliografia } \\
\text { base }\end{array}$ & - Tavares, A.C. \& Pereira G. (2018); - Tavares, A.C. (2018). \\
\hline Produtos: & \\
\hline
\end{tabular}

Rev. Eletrônica Mestr. Educ. Ambient. Rio Grande. v. 36, n. 3. Seção especial: V Congresso Internacional de Educação Ambiental dos Países e Comunidades de Língua Portuguesa. p. 292-318. Set/Dez. 2019. 


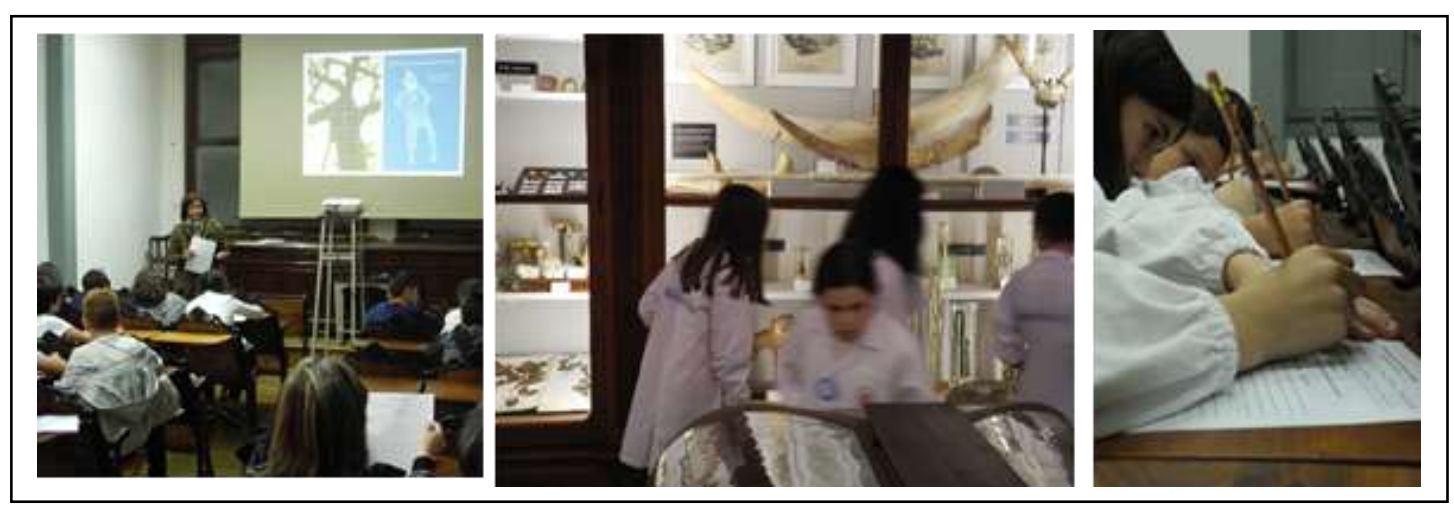

Figura 4 - Apresentação do livro "O índio que queria conhecer o mundo", a descoberta dos protagonistas do livro e outros exemplares do Museu e avaliação da ação pelos alunos.

\section{AVALIAÇÃo}

O progresso de aprendizagem e reação dos alunos foi monitorizado por (pré e pós) questionários, em análise e a publicar oportunamente com os colegas do Museu da Ciência da Universidade de Coimbra, Gilberto Pereira e José Cid Gomes.

\begin{tabular}{|c|c|}
\hline \multicolumn{2}{|c|}{ PRÉ-Questionário (em sala, antes da ação) } \\
\hline $\begin{array}{l}\text { 1. Sabes para que serve um museu? } \\
\text { modo breve: }\end{array}$ & Se sim, explica de um \\
\hline 2. Conheces alguns objetos deste museu? & Se sim, dá exemplos: \\
\hline $\begin{array}{l}\text { 3. Haverá no museu plantas ou animais em vias de extinção? } \\
\text { Se sim, quais: }\end{array}$ & Sim Não \\
\hline 4. Algum comentário que queiras fazer antes da visita? & \\
\hline
\end{tabular}

PÓS-Questionário 1. (em sala, no museu, terminada a ação, percecionando conhecimentos apreendidos sobre a história e a relação com o museu)

1. Gostaste da história do Índio que queria conhecer o mundo? Sim Não Porquê?

2. Conseguiste encontrar no Museu alguns intervenientes da história? Sim Não Se sim, quantos e dá exemplos:

3. De qual gostaste mais? Porque:

4. De qual gostaste menos? Porque:

5. Convidamos-te a escrever ou desenhar uma história tua sobre o Museu, com fotografias digitalmente modificadas e vir cá apresentar. Podemos contar contigo? Sim Não

\begin{tabular}{|llll|}
\hline \multicolumn{4}{|c|}{ PÓS-Questionário 2. (em sala, na escola, percecionando conhecimentos } \\
apreendidos & sobre o museu) & \\
\hline $\begin{array}{l}\text { 6. Sabes para que serve um museu? } \\
\text { modo breve: }\end{array}$ & Sim & Não. & Se sim, explica de um \\
\hline 7. Conheces alguns objetos deste museu? & Sim & Não. .....Se sim, dá exemplos: \\
\hline 8. Haverá no museu exeplared de plantas & ou animais em vias de extinção? & Sim \\
\hline
\end{tabular}

Rev. Eletrônica Mestr. Educ. Ambient. Rio Grande. v. 36, n. 3. Seção especial: V Congresso Internacional de Educação Ambiental dos Países e Comunidades de Língua Portuguesa. p. 292-318. Set/Dez. 2019. 


\begin{tabular}{|l|}
\hline Não \\
Se sim, quais: \\
\hline 9. Algum comentário que queiras fazer depois da visita? \\
\hline 10. Gostarias de voltar ao Museu? Porquê? \\
\hline
\end{tabular}

\section{$3^{\circ}$ CASO: SESSENTA MINUTOS NO DESERTO COM WELWITSCHIA}

\section{MIRABILIS}

Vocacionado para um público adulto, esta temática tem sido abordada em palestras e, casuisticamente, junto aos espécimes na sala de África, como ilustra a figura 2, ações educativas suscetíveis de ser avaliadas por instrumentes como registo de observações e/ou questionários de avaliação.

Já numa segunda edição, o livro "Sessenta Minutos no Deserto com ... Welwitschia mirabilis!" aborda muitas matérias, de modo que o título poderia ser: "Do Lubango ao Namibe" ou "Do Jurássico à atualidade", "Um caso de resiliência", "Exemplos de Conservação in vivo, in vitro e ex situ", "Sobreviveu aos dinossauros", "Uma proeza fantástica e enriquecedora pelo Namibe" ou "História da Vida na Terra contada por um endemismo". Apresenta uma compilação de documentos e conhecimentos multidisciplinares, desde Biologia, a Geologia, Antropologia e História da Ciência. Orienta o leitor através da realidade angolana de hoje e do seu património natural, científico e cultural, e pode ser usado como um guia para explorar a Sala de África do Museu da Ciência, onde o público pode encontrar alguns exemplares de Welwitschia, trazidos do deserto de Moçâmedes (Angola) há mais de 200 anos e pela autora em 2016 (Fig. 2). Relatando histórias vivenciadas pela autora, apresenta elementos narrativos de caráter pessoal, permite um diálogo muito próximo entre a realidade, a Welwitschia no Museu e os seus visitantes, revelando-se facilmente convincente quanto à mensagem sobre a necessidade de preservar a biodiversidade, com sustentabilidade.

\section{RESULTADOS E DISCUSSÃO}

Apresentada a metodologia, a estrutura, os conteúdos e o formato avaliativo dos três casos-estudo avançamos com uma análise dos níveis de consciencialização, curiosidade e/ou conhecimento demonstrados pelos participantes

De acordo com os objetivos e metas curriculares do $5^{\circ}$ ano das Ciências Naturais (CALDAS \& PESTANA), desenvolveu-se uma aula onde o aluno é convidado a desenvolver um papel ativo, um trabalho mais autónomo na construção da sua Rev. Eletrônica Mestr. Educ. Ambient. Rio Grande. v. 36, n. 3. Seção especial: V Congresso Internacional de Educação Ambiental dos Países e Comunidades de Língua Portuguesa. p. 292-318. Set/Dez. 2019. 
aprendizagem, por ele próprio e em diálogo com o professor e inserido num grupo de trabalho. Em contato direto com diferentes plantas, exemplos naturais e recursos educativos de excelência, na atividade baseada na exploração do livro "A Alga que queria ser flor", os produtos executados pelos alunos, ao inventar outra história, uma música, um desenham e a organização de coleções de plantas, refletem o conhecimento adquirido. As crianças contactaram com o mundo das algas microscópicas, observando várias amostras, como algas azuis, castanhas, vermelhas e verdes, as ancestrais das plantas, avançando um pouco também no percurso evolutivo das algas. Nesta atividade, o aluno usa exemplos vivos, a maioria dos quais conhece do seu dia-a-dia, e assim pode despertar o seu interesse e consciência para a realidade.

Estas e outras aulas fora da sala de aula foram integradas durante as aulas em contexto formal, ensinando e ligando diferentes disciplinas, como Biologia e Música, permitindo o trabalho em equipa multidisciplinar que resultou numa música elaborada a partir dos textos escritos pelos alunos do $5^{\mathrm{o}}$ ano, inspirados na história, e que foi apresentada na festa de final de ano da escola. A aprendizagem e as atitudes dos alunos foram avaliadas aplicando pré e pós-questionários, em que os jovens alunos, de 7 a 12 anos de idade. De um modo geral verificou-se que novos conceitos e atitudes sobre as plantas foram aprendidos, independentemente da idade (TAVARES; CABRAL \& ALVES, 2015a,b): 'Conhecer os cinco grupos de plantas e sua evolução' foi novo conhecimento adquirido, conseguido por mais de $50 \%$ dos alunos. A maioria dos alunos apreciou esta experiência educativa, principalmente porque 'Aprenderam mais'. No geral, os alunos 'Sentiram-se mais inspirados' e mais 'Dispostos a adotar novas atitudes sobre a natureza' a (TAVARES, 2017b).

A história "O índio que queria conhecer o mundo" decorre no Museu da Ciência da Universidade de Coimbra, ilustrando vários aspetos da biodiversidade e a importância da sua conservação. O autor adota uma metodologia construtivista, destinada a evidenciar conteúdos da biodiversidade e, ao complementar os conteúdos da ciência e interligando outras disciplinas, como as artes performativas, para finalizar a trama em comemoração, o texto científico encontra o currículo escolar, particularmente o $5^{\circ}$ ano (CALDAS \& PESTANA, 2010). O foco é entender a biodiversidade e sua conservação e a importância da missão dos museus de ciência a esse respeito, no que diz respeito à preservação do patrimônio do passado, gostando do presente e projetando-o no futuro.

Rev. Eletrônica Mestr. Educ. Ambient. Rio Grande. v. 36, n. 3. Seção especial: V Congresso Internacional de Educação Ambiental dos Países e Comunidades de Língua Portuguesa. p. 292-318. Set/Dez. 2019. 
Dois objetos etnográficos (uma máscara indígena de Angola, Mukixi e outra do Brasil, Tikuna) são os heróis de uma aventura através do Gabinete de Física e Galeria de História Natural, interagindo com outros espécimes científicos, alguns representando espécies ameaçadas de extinção (TAVARES, 2018; TAVARES \& PEREIRA, 2018). Ao saírem das "vitrinas" metaforicamente "saem" da ignorância e o Museu é para eles, como para qualquer visitante, um lugar de admiração onde eles descobrem instrumentos, animais e plantas, como numa arca gigantesca. Há histórias notáveis, mas verdadeiras, associadas a muitos dos objetos do Museu, sendo o ímã montado em uma coroa real, a planta de dois séculos atrás, o enorme esqueleto de baleia ou o lince ibérico à beira da extinção. Os visitantes, meninos e meninas, vestem "a pele" e assumem a experiência dos dois principiais protagonista da história, o Mukixi e a índia Tikuna. Começando o exercício de observação através do museu, construem um enredo para uma história de ciência, que é uma representação da marca de identidade e uma interpretação da biografia dos objetos (acessível on-line no museu digital MCUC, por nome comum, científico nome ou número de inventário), e dá origem a um diálogo e a um discurso de conceitos científicos.

Um museu mantém-se vivo na medida em que comunica através de uma linguagem própria e atrai o visitante para os seus objetos e coleções, e "objetos e observadores são atores da história" (PEARCE, 1992, p.264). Semelhante a outras ações em museus (HOOPER-GREENHILL, 2011; WITCOMB, 2011), o diálogo museológico construído sobre os objetos da exposição permanente e as histórias interpretativas envolvem a construção de significados e despertam interesses e curiosidades sobre o mundo natural, especialmente em crianças, aprendizes em desenvolvimento. Emergem num discurso exploratório e transformam o espaço num cenário em que os observadores são convidados a ser parte ativa. Há também oportunidade para representações afetivas e emocionais no decorrer das histórias e das atividades construídas sobre elas, expressões estéticas e poéticas sobre a beleza dos objetos e do espaço, que podem provocar sentimentos de surpresa, medo, cumplicidade, paixão e descoberta. Especificamente através da biografia de um objeto, os alunos ou qualquer visitante do Museu da Ciência podem explorar diferentes conceitos, temas e disciplinas. Há também a oportunidade de expandir essas estratégias para outras realidades do mundo natural e ajustá-las a diferentes públicos.

A história "Sessenta Minutos no Deserto com ... Welwitschia mirabilis!" contém elementos narrativos clássicos de caráter, conflito, tensão e resolução conduzindo o leitor através da realidade angolana e abordando muitos conceitos científicos, como a resiliência 
das plantas, o endemismo, a conservação in vivo, in vitro e ex situ. Tanto os professores como os alunos podem usar o livro como guia através da galeria de África do Museu da Ciência, onde são estão expostos alguns exemplares de Welwitschia. Os mais antigos foram recolhidos em 1927-37 por Luis Carrisso e os mais recentes, cones e sementes, recolhidos em 2016 por Tavares (2017a). Estão rodeados por outros exemplares, de fauna e flora abordados no livro e típicos desse habitat tão específico.

Num exercício de observação e interpretação da Natureza, criaram-se narrativas da ciência, sobre diversidade e sustentabilidade, onde é intencional a referência à Welwitschia mirabilis nas 3 histórias, em diferentes perspetivas e análises. Abarcando todos os públicos, desde a pré-primária ao adulto, reforça se a importância científica desta espécie, exemplo real de muitos conceitos científicos, endemismo, fóssil vivo, relíquia do jurássico, uma raridade preservada no Museu da Ciência.

Este estudo expõe e propõe o uso de histórias isoladas, em contexto de sala de aula ou informal, como componentes de um tema narrativo abrangente, ecologia $\mathrm{e}$ sustentabilidade, vocacionado particularmente para as crianças, mas também para os adultos, a assimilarem mais facilmente uma série de eventos e fenómenos científicos relacionados com fatos científicos do quotidiano. Segundo Falk e colaboradores (2011) e Wagensberg (2005), a aprendizagem em museus ocorre ao longo do tempo, geralmente em dois padrões paralelos, ideias ou fatos globais e conceitos, num processo cumulativo de aquisição e consolidação do conhecimento, convidando o raciocínio e o pensamento individual. Tendo isso em conta, ao uso dessas histórias em contexto educacional, seja na sala de aula, no espaço natural ou no próprio museu, pode seguir-se uma discussão / reflexão sobre os temas, aprofundando os conteúdos e a análise de identidade dos objetos, sondando opiniões, interdisciplinaridade e conexões com o mundo real. Sugere-se que os participantes compartilhem e criem pequenos projetos, histórias ou obras de arte, com o mesmo ou outros objetos do jardim e museu, outra representação museológico-científica, num processo aberto, a apresentar no museu ou na escola ou, podendo servir como instrumentos para avaliação retrospetiva e sumativa.

Os museus atualmente enfrentam uma mudança de foco da sua ação, de uma massa de público indiferenciado para intérpretes e protagonistas ativos (HOOPER-GREENHILL, 2011; FALK, DIERKING \& ADAMS, 2011) e novos requisitos no formato de disseminação da informação são exigidas e cruciais. Outros autores afirmaram que "o sucesso na criação de respostas emocionais em torno de histórias científicas pode ser a 
chave para tornar a ciência uma paixão pelas gerações futuras" (LINETT, 2013) e "o diálogo pode tornar-se a base para uma nova compreensão da interatividade do museu" (WITCOMB, 2011).

Concluímos referindo que em muitas ocasiões, as estratégias de ficção narrativa podem ser mais apropriadas para representar a ciência do que as práticas textuais expositivas que dominaram a ciência e a educação ambiental até hoje. Nestes três exemplos analisados, propostas de instrumentos pedagógicas (haverá muitos outros) para a eficácia educativa, o discurso é encadeado e objetivo e desperta o interlocutor para a realidade, prendendo a atenção e aguçando a curiosidade. Envolvidos nos fatos narrados, os leitores esperam por um fim, feliz ou trágico, porque querem entender todo o conteúdo e depois agir, ou pelo menos raciocinar e refletir sobre o assunto, etapa indispensável à aquisição de conhecimento e mudança de comportamentos, que se deseja em prol da sustentabilidade.

\section{REFERÊNCIAS}

AMARAL, S.; MONTENEGRO, M.; FREITAS, F.; FORTE, T.; GIRÃO DA CRUZ, T. Science in Theatre-An Art Project with Researchers. Journal of Creative Communications, v. 12, n. 1, p. 1-18, 2017.

AUNOLA, K.; VILJARANTA, J.; LEHTINEN, E.; NURMI, J. The Role of Maternal Support of Competence, Autonomy and Relatedness in Children's Interests and Mastery Orientation. Learning and Individual Differences, v. 25, p. 171-177, 2013.

AVRAAMIDOU, L; OSBORNE, J. The Role of Narrative in Communicating Science. International Journal of Science Education, v. 31:12, p. 1683-1707, 2009.

BELL, James; FALK, John; HUGHES, ROXANNE; TROXEL, Geoff. Informal STEM Education: Resources for Outreach, Engagement and Broader Impacts. Washington, DC: Center for Advancement of Informal Science Education, 2016.

BIETTI, L.M.; TILSTON, O.; BANGERTER A. Storytelling as Adaptive Collective Sensemaking. Topics in Cognitive Science, p. 1-23, 2018.

BRAY, B.; FRANCE, B.; GILBERT, J. K. Identifying the Essential Elements of Effective Science Communication: What do the experts say? International Journal of Science Education, v. 2, n. 1, p. 23-41, 2012.

BROMELY, Gail; REGAN, Ellen; KAPELARI, Susan; DILLON, John; VERGOU, Asimina; WILLISON, Julia; BONOMI, Constantino; PAIVA, Isabel; SANTOS, Joaquim; TAVARES, Ana Cristina (2013). O manual do curso Inquire, Projeto INQUIRE, 2013, Coimbra, Portugal: Projeto Inquire. 2013.

Rev. Eletrônica Mestr. Educ. Ambient. Rio Grande. v. 36, n. 3. Seção especial: V Congresso Internacional de Educação Ambiental dos Países e Comunidades de Língua Portuguesa. p. 292-318. Set/Dez. 2019. 
CALDAS, Isabel; PESTANA, Isabel. Ciências da Natureza ( $5^{\circ}$ ano): Projeto Desafios. Carnaxide: Santillana Constância Editores, 2010.

DAHLSTROM, M. Using narratives and storytelling to communicate science with nonexpert audiences. PNAS, v. 11, n. 4, 13614-13620, 2014.

DILLON, J.; DEWITT, J.; PEGRAM, E.; IRWIN, B.; CROWLEY, K.; KING, H.; KNUTSON, K.; VEALL, D.; XANTHOUDAKI, M. A Learning Research Agenda for Natural History Institutions. London: Natural History Museum, 2016.

DILLON, J.; RICKINSON, M.; TEAMEY, K; MORRIS, M. The value of outdoor learning: evidence from research in the UK and elsewhere. School Science Review, v. 87, n. 320 , p. $107-111,2006$.

DRISSNER, J.; HAASE, H.; HILLE, K. Short-term environmental education - does it work? - An evaluation of the 'green classroom'. Journal of Biological Education, v. 44, n. 4 , p. $149-55,2010$.

FALK, J. H.; DIERKING, L. D.; ADAMS, M. Living in a Learning Society: Museums and Free-choice Learning. In: A Companion to Museum Studies. Edited by Sharon Macdonald, Wiley. 2011.

FANČOVIČOVÁ, J.; PROKOP, P. Plants have a chance outdoor: Educational programmes alter students' knowledge and attitudes towards plants. Environmental Education Research, v. 17 n. 4, p. 537-551, 2011.

FLEER, M.; HAO, Y. Studying the landscape of families and children's emotional engagement in science across cultural contexts. International Research in Early Childhood Education, v. 7, n. 1, p. 183-201, 2016.

FRACALANZA, H.; MEGID-NETO, J. O livro didático de ciências: o que nos dizem os professores, as pesquisas acadêmicas e os documentos oficiais. Ciência \& Educação, v. 9, n. 1, p. 93-104, 2003.

FREZZA, G. Metaphor: the good argument in science communication. RIFL, v. 2, p. 2133, 2016.

HEIN, G. E. Museum Education. In: A Companion to Museum Studies. Edited by Sharon Macdonald, Wiley-Blackwell Publishing Ltd. John Wiley \& Sons Ltd, United Kingdom, 2011.

HILLIER, A.; KELLY, R.; KLINGER, T. Narrative style Influences citation Frequency in Climate changes. PLoS ONE, v. 11, n. 12: e0167983. 2016.

HOOPER-GREENHILL, Eilean. Studying Visitors. In: A Companion to Museum Studies. Edited by Sharon Macdonald. Wiley-Blackwell Publishing Ltd. John Wiley \& Sons Ltd, United Kingdom, 2011.

JONES, M.D.; CROW, D. A. How can we use the 'science of stories' to produce persuasive Gail; VERGOU, ASIMINA; WILLISON, Julia. Train the Trainer - The

Rev. Eletrônica Mestr. Educ. Ambient. Rio Grande. v. 36, n. 3. Seção especial: V Congresso Internacional de Educação Ambiental dos Países e Comunidades de Língua Portuguesa. p. 292-318. Set/Dez. 2019. 
INQUIRE Course Manual, London: BGCI, 2013.scientific stories? Palgrave Communications, v. 3, n. 53. 2017.

KAPELARI, Susan; BONOMI, Constantino; DILLON, John; REGAN, Ellen; BROMLEY,

KEYSERS, C.; GAZZOLA, V. Expanding the mirror: Vicarious activity for actions, emotions, and sensations. Current opinion in neurobiology, v. 19, n. 6, p. 666-71. 2009.

KRAUS, N.; WHITE-SCHWOCH, T. Neurobiology of everyday communication: what have we learned from music? The Neuroscientist, v. 23, n. 3, p. 287-298. 2017.

KRAUSE, R.J.; RUCKER, D. D. Strategic Storytelling: When Narratives Help Versus Hurt the Persuasive Power of Facts. Pers Soc Psychol Bull.

Jun10:146167219853845146167219853845. 2019.

LAAKSOHARJU, T.; RAPPE, E. Children's relationship to plants among primary school children in Finland: Comparisons by location and gender. HortTechnology, v. 20, n. 4, p. 689-695. 2010.

LINDEMANN-MATTHIES, P. 'Loveable' mammals and 'lifeless' plants: how children's interest in common local organisms can be enhanced through observation of nature.

International Journal of Science Education, v. 27, n. 6, p. 655-677. 2005

LINDEMANN-MATTHIES, P.; COSTAS, C.; LEHERT, H.-J.; NAGEL, U.; RAPER, G.; KADJI-BELTRAN, C. Confidence and Perceived Competence of Preservice Teachers to Implement Biodiversity Education in Primary Schools-Four comparative case studies from Europe, International Journal of Science Education, v. 33, n. 16, p. 2247-2273. 2011. LINETT, P. Interview with Ben Lillie on Science and the Story Collider. Curator, v. 56, n. 1, p. 15-19. 2013.

LOHR, V.; PEARSON-MIMS, C. Children's active and passive interactions with plants influence their attitudes and actions toward trees and gardening as adults.

HortTechnology, v. 15, n. 3, p. 472-476. 2005.

MARTINEZ-CONDE, S.; MACKNIK, S.L. Opinion: Finding the plot in science storytelling in hopes of enhancing science communication. Proceedings of the National Academy of Sciences. PNAS. v. 114, n. 31, p. 8127-8129. 2017.

MATTEMAN, Y.; DAMSA, W. Research-minded education in Science Museums. Spokes, v. 27, p. 1-14. 2017.

MCKINNON, M.; VOS, J. Engagement as a Threshold Concept for Science Education and Science Communication. International Journal of Science Education, Part B, v. 5, n. 4, p. 297-318. 2015.

MCSILL, John. 5 Lições de StoryTelling: Fatos, Ficção e Fantasia. Editora TopBooks: Rio de Janeiro, Brasil. 2015.

MONTENEGRO, Mário. A emergência da Ciência Moderna e a sua representação no texto dramático. Tese de Doutoramento, Faculdade de Letras da Universidade de Coimbra. 2016.

Rev. Eletrônica Mestr. Educ. Ambient. Rio Grande. v. 36, n. 3. Seção especial: V Congresso Internacional de Educação Ambiental dos Países e Comunidades de Língua Portuguesa. p. 292-318. Set/Dez. 2019.

E-ISSN 1517-1256 
NATIONAL ACADEMIES OF SCIENCES, ENGINEERING, AND MEDICINE. Communicating Science Effectively: A Research Agenda. Washington, DC: The National Academies Press. 2017.

OSBORNE, J.; DILLON, J.. Science Education in Europe: Critical Reflections. A Report to the Nuffield Foundation. London: King's College of London. 2008.

PANY, P.; LÖRNITZO, A.; LISA AULEITNER, L.; HEIDINGER, C.; LAMPERT, P.; KIEHN, M. Using students' interest in useful plants to encourage plant vision in the classroom. Plant Science Bulletin, v. 60, n. 1, p. 18-27, 2019.

PEARCE, Susan. Museums, Objects and Collections. Smithsonian Institution Press: Washington DC., 1992.

RANDLER, C.; OSTI, J.; HUMMEL, E. Decline in Interest in Biology among Elementary School Pupils during a Generation. Eurasia Journal of Mathematics, Science \&Technology Education, v. 8, n. 3, p. 201-205. 2012.

REIS, Marlene Barbosa de Freitas, LIMA, Daniela da Costa Brito Pereira, DESIDERIO, Mónica. Desenvolvimento, educação e sustentabilidade: questões emergentes e desafiadoras. Rev. Electronica Mestr. Edu. Ambien. Rio Grande, v. 35, n.3, p. 4-22, set./dez. 2018.

ROSE, J.A. To Teach Science, Tell Stories. Project Master of Arts in the Graduate Liberal Studies Program in the Graduate School: Department of Biology, Duke University. 2017.

SANDERS, D. L. Making public the private life of plants: the contribution of informal learning environments. International Journal of Science Education, v. 29, n. 10, p. 1209-1228. 2007.

TAVARES, A.C. A alga que queria ser flor/The algae who wanted to be a flower. Imprensa da Universidade de Coimbra: Coimbra, Portugal. Livro bilingue, em cinco versões. 2013.

TAVARES, A.C. Educação em Jardins Botânicos - 16 anos de experiência. Málaga: Eumed - Universidade de Málaga. In: http://www.eumed.net/librosgratis/2015/1442/index.htm. 2015.

TAVARES, A.C. Sessenta minutos no des erto com... Welwitschia mirabilis! Edições MinervaCoimbra: Coimbra, Portugal. 2017a.

TAVARES, A.C. Metodologia IBSE no ensino aprendizagem das ciências da natureza: casos de estudo em espaços exteriores à sala de aula. Relatório de Pósdoutoramento. Faculdade de Psicologia e Educação da Universidade Católica do Porto, Centro de Estudos em Desenvolvimento Humano. Biblioteca virtual Eumed, Universidade de Valencia. http://www.eumed.net/libros/libro.php?id=1666. 2017b.

Rev. Eletrônica Mestr. Educ. Ambient. Rio Grande. v. 36, n. 3. Seção especial: V Congresso Internacional de Educação Ambiental dos Países e Comunidades de Língua Portuguesa. p. 292-318. Set/Dez. 2019. 
TAVARES, A.C. Diálogo museológico interdisciplinar em prol da biodiversidade: um evento performativo. Aula, Museos y Colecciones de Ciencias Naturales, Real Sociedad Española de Historia Natural, v. 5, p. 83-97. 2018.

TAVARES, A.C.; PEREIRA G. O Índio que queria conhecer o mundo. Edição de autor. Coimbra, Portugal. $1^{\mathrm{a}}$ Edição, novembro 2018.

TAVARES, A.C.; CABRAL, I.; ALVES, J. M. Alunos jovens (7 a 12 anos de idade) podem aprender a importância e a evolução das plantas? Casos de estudo com a metodologia IBSE. 23 e 24 de Julho 2015, Universidade Católica Portuguesa do Porto. Faculdade de Educação e Psicologia. Atas do I Seminário Internacional sobre Educação, Território e Desenvolvimento Humano, Vol. II., 95-109. Editor: Universidade Católica Portuguesa do Porto. Faculdade de Educação e Psicologia: Porto. 2015a.

TAVARES, A.C.; CABRAL, I.; ALVES, J. M. Teaching and learning Natural Sciences with IBSE methodology: a study outside classroom. END 2015. 27-29 June, 2015, Porto. Portugal. International Conference on Education and New Developments Proceedings Book. Edited by Mafalda do Carmo, World Institute for Advanced Research Science (WIARS), Lisbon, Portugal. 2015b. p. 616-619.

TAVARES, A.C.; SILVA, S.; BETTENCOURT, T. Advantages of Science Education Outdoors through IBSE Methodology. In: Patrick Blessinger, John M. Carfora (ed.) Inquiry-Based Learning for Science, Technology, Engineering, and Math (Stem) Programs: A Conceptual and Practical Resource for Educators (Innovations in Higher Education Teaching and Learning, v. 4. Emerald Group Publishing Limited, pp.151-169. Editor(s): Patrick Blessinger, John M. Carfora. 2015a.

TAYLOR, C.; DEWSBURY, B.M. On the Problem and Promise of Metaphor Use in Science and Science Communication. Journal of Microbiology \& Biology Education, v. 19 , n. 1, p. 1-5, 2018.

VAN AALDEREN-SMEETS, S.; VAN DER MOLEN, J.; VAN HEST, E.; POORTMAN, C. G. Primary teachers conducting inquiry projects: effects on attitudes towards teaching science and conducting inquiry. Intemational Journal of Science Education, v. 39, n. 2, p. 238-256, 2017.

VASCONCELOS, C.; TORRES, J.; MOUTINHO, S.; MARTINS, I.; COSTA, N. Uncovering Portuguese teachers' difficulties in implementing sciences curriculum. Cogent Education, v. 2, n. 1, p. 1060755. 2015.

VON MOSSNER, A.W. Affective Ecologies: Empathy, Emotion, and Environmental Narrative. Frederick Luis Aldama, Patrick Colm Hogan, Lalita Pandit Hogan, and Sue Kim, Series Editors. Ohio State University: Press Columbus. 2017.

WAGENSBERG, J. The "total" museum, a tool for social change. História Ciências Saúde-Manguinhos, v. 12(Suppl), p. 309-321, 2005. 
WANDERSEE, J.; SCHUSSLER, E. Toward a theory of plant blindness. Plant Science Bulletin, v. 47, n. 1, p. 2-9, 2001.

WITCOMB, A. Interactivity: Thinking Beyond. In: A Companion to Museum Studies. Edited by Sharon Macdonald. Wiley-Blackwell Publishing Ltd. John Wiley \& Sons Ltd, United Kingdom, 2011.

YOREK, N.; ŞAHIN, M.; AYDIN, H. Are Animals 'More Alive' than Plants? AnimisticAnthropocentric Construction of Life Concept. Eurasia Journal of Mathematics Science \& Technology Education, v. 5, n. 4, p. 371-380, 2009.

ZABEL, J. Narrative and Metaphor as Conceptual Tools for Understanding Evolution Theory. Proceedings of the International Conference Innovazione nella didattica delle scienze nella scuola primaria e dell'infanzia, p. 1-18, 2014.

ZACK, P.J. Why Inspiring Stories Make Us React: The Neuroscience of Narrative.

Cerebrum, v. 2, 2015. 